\title{
COMPARING EXTERNAL TOTAL LOAD, ACCELERATION AND DECELERATION OUTPUTS IN ELITE BASKETBALL PLAYERS ACROSS POSITIONS DURING MATCH PLAY
}

\author{
Jairo Vázquez-Guerrero ${ }^{1}$, Luis Suarez-Arrones ${ }^{2}$, \\ David Casamichana Gómez ${ }^{3}$, and Gil Rodas ${ }^{1}$ \\ ${ }^{1}$ Medical Department, Football Club Barcelona, Barcelona, Spain \\ ${ }^{2}$ Faculty of Sport, Pablo de Olavide University, Sevilla, Spain \\ ${ }^{3}$ Faculty of Physiotherapy and Speech Therapy Gimbernat-Cantabria University \\ School associated with the University of Cantabria (UC), Torrelavega, Spain
}

Original scientific paper

https://doi.org/10.26582/k.50.2.11

UDC: $796.011 .3: 796.323 .2$

\begin{abstract}
:
The aim of this study was to compare external load, calculated by an accelerometer training load model, the number and intensity of accelerations and decelerations, and the acceleration:deceleration ratio between playing positions during basketball matches. Twelve elite male basketball players (mean $\pm \mathrm{SD}$, age: $25.5 \pm 5.2$ years (range: $19-36$ years); body height $201.4 \pm 8.6 \mathrm{~cm}$; body mass: $98.4 \pm 12.6 \mathrm{~kg}$ ) were monitored during two official matches. An accelerometer training load model and the number of accelerations and decelerations were used to assess physical demands imposed on basketball players. Magnitude-based inferences and effect sizes (ES) were used to assess possible differences between positions: point guards (PG), shooting guards (SG), small forwards (SF), power forwards (PF) and centers (C). Elite basketball players in all positions presented higher maximal decelerations than accelerations ( $\mathrm{ES}=2.70$ to 6.87 ), whereas the number of moderate accelerations were higher than the number of moderate decelerations ( $E S=0.54$ to 3.12). Furthermore, the acceleration:deceleration ratio $\left(>3 \mathrm{~m} \cdot \mathrm{s}^{-2}\right)$ was significantly lower in players on the perimeter (PG and SG) than in PF and $\mathrm{C}$ ( $\mathrm{ES}=1.03$ to 2.21). Finally, PF had the lowest total external load ( $\mathrm{ES}=0.67$ to 1.18). These data allow us to enlarge knowledge of the external demands in basketball matches and this information could be used in the planning of training programs.
\end{abstract}

Key words: team sports, accelerometer, sport performance, GPS, training

\section{Introduction}

High demands in basketball produce major physiological and neuromuscular loads on players during competition (McInnes, Carlson, Jones, \& McKenna, 1995). Modern basketball matches comprise around 1000 actions (Ben Abdelkrim, El Fazaa, \& El Ati, 2007), of which $11.5 \%$ require maximum intensity (Ben Abdelkrim, Castagna, et al., 2010). The duration of high intensity actions ranges between 2 and $5 \mathrm{~s}$ (Hoffman \& Maresch, 2000), with a mean workto-rest ratio of 1:10 when considering maximum effort actions (Ben Abdelkrim, Castagna, et al., 2010; Hoffman \& Maresch, 2010; McInnes, et al., 1995). In this way, basketball players are required to perform lower-body explosive actions such as sprints, jumps, accelerations and decelerations (Ben Abdelkrim, et al., 2007).

Monitoring and management of the training load in team sports has received increased attention in recent years (Soligard, et al., 2016). It is important to monitor individual training load during training sessions and competitive matches to determine whether athletes are achieving the physical targets proposed (Scott, Lockie, Knight, Clark, \& Janse de Jonge, 2013). Orchard (2012) hypothesized excessive and unsuitable workloads would lead to reduced sport performance or augmented injury occurrence. Understanding the influence of training load outcomes on sport performance and injury prevention should be considered as vital in sport medicine and for strength and conditioning coaches and sport scientists (Soligard, et al., 2016). Essentially, sport scientists acquire measurements of a programmed external training load (i.e., physical 'work' based on movement), accompanied by an internal training load response (i.e., perceived fatigue or physiological changes) (Soligard, et al., 2016). External training loads may include 
total distance run, number of sprints, high speed running, accelerations, decelerations, jumps or impacts (Soligard, et al., 2016). Individual player profiles (e.g., training age, chronological age, physical capacity and injury history) associated with the internal and external training loads achieved determine the training and/or match-play outcome (Soligard, et al., 2016).

While the internal load includes ratings of perceived exertion (Manzi, et al., 2010) and heart rate responses (Ben Abdelkrim, et al., 2007; Manzi, et al., 2010) and has been studied in elite basketball match play, the external load has been assessed in few research studies (Montgomery, Pyne, \& Minahan, 2010; Puente, Abián-Vicén, Areces, López, \& Del Coso, 2017) using specific technologies in this setting. Although recent advances in methods have created various external measures such as global positioning systems (GPS) to estimate the intensity of exercise and training external loads in outdoor team sports (Scott, M.T., Scott, T.J., \& Kelly, 2016), this approach is impractical for indoor sports such as basketball due to inability to interact with satellites' signals (Dobson \& Keogh, 2007).

Accelerometry overcomes some of the limitations associated with time-motion video analyses and GPS technologies such as the low sampling frequency and the non-consideration of movements made in the frontal plane, such as jumps (Scott, Scott, \& Kelly, 2016). The use of smart sensor devices such as triaxial accelerometers, which are relatively unobtrusive during training and competition, has aroused interest as a method to monitor external training load in team sports (Boyd, Ball, \& Aughey, 2011; Montgomery, et al., 2010; Scanlan, Wen, Tucker, \& Dalbo, 2014; Scott, Lockie, et al., 2013). When studying the physical demands of basketball match-play with video analyses, gross locomotion is categorized using several speed thresholds ranging from motionless standing to sprinting (Ben Abdelkrim, et al., 2007). However, this method neglects accelerations and decelerations (Akenhead, Hayes, Thompson, \& French, 2013; Varley, Fairweather, \& Aughey, 2012). Acceleration precedes high speed running (di Prampero, et al., 2005) and requires high rates of force development, but it is a distinct phenomenon (di Prampero, et al., 2005) which requires higher neural activity of the working muscles than it does constant speed sprinting (Mero \& Komi, 1987) as described by Akenhead et al. (2013). Acceleration is vital in decisive activities in order to obtain advantages during team sports (Carling, Bloomfield, Nelsen \& Reilly, 2008). Therefore, in order to quantify external load in team sports it is important to establish the number of high intensity actions such as accelerations and decelerations (Gabbett, Wiig, \& Spencer, 2013). Specifically, an accelerometer training load model has been used to monitor external training load during basketball training (Montgomery, et al., 2010). Scanlan et al. (2014) used a similar accelerometer training load algorithm to monitor external training load during the preparatory phase of the annual training plan in semiprofessional male basketball players. To date, however, no model has been used to assess the external load, the number of accelerations (concentric muscular action) and decelerations (eccentric muscular action), and the acceleration:deceleration ratio in professional male basketball players during an official match play. This ratio could be an interesting indicator to know the importance of one type of action relative to the other.

Basketball team playing positions are in general classified into three playing specific positions: guards, forwards and centers (Ben Abdelkrim, Chaouachi, Chamari, Chtara, \& Castagna, 2010). Prior research has reported differences between positional roles in aerobic and anaerobic power (Pojskić, Šeparović, Užičanin, Muratović, \& Mačković, 2015), maximal aerobic power (Cormery, Marcil, \& Bouvard, 2008; Ostojic, Mazic, \& Dikic, 2006; Sallet, Perrier, Ferret, Vitelli, \& Baverel, 2005), speed (Smith \& Thomas, 1991), height (Ackland, Schreiner, \& Kerr, 1997; Bale, 1991; Ostojic, et al., 2006; Sallet, et al., 2005), body mass (Latin, et al., 2009; Ostojic, et al., 2006; Sallet, et al., 2005) and body fat (Latin, Berg, \& Baechle, 2009; Ostojic, et al., 2006; Sallet, et al., 2005) in men's senior basketball. However, positions should attend to the specific role within the competition: point guard (PG), shooting guard (SG), small forward (SF), power forward (PF) and center (C) (Ben Abdelkrim, et al., 2010). Although the analysis of competition is vital to train most effectively (Gabbet, 2016), no information is currently available on the total external loading and the number of accelerations and decelerations experienced by elite basketball players during match play relative to playing position.

Thus, the aim of this study was to compare the total external load calculated by an accelerometer training load model, the number of accelerations and decelerations and the acceleration:deceleration ratio at different velocities between specific positions in elite senior basketball players during competitive matches.

\section{Methods}

\section{Participants}

Twelve elite male basketball players (mean $\pm \mathrm{SD}$, age: $25.5 \pm 5.2$ years [range: $19-36$ years]; body height $201.4 \pm 8.6 \mathrm{~cm}$; body mass: $98.4 \pm 12.6 \mathrm{~kg}$ ) volunteered to participate in the study. The players played for the team ranked in one of the top three teams in the Spanish Basketball League (ACB) in the 2014/15 
Championship. All players were screened for health conditions and injuries that contraindicated participation. All players were verbally informed of the study requirements, and provided written informed consent. The research procedures were approved by an Institutional Human Research Ethics Committee in accordance with the Helsinki Declaration.

\section{Procedure}

In this study, an observational design was used to examine the physical demands imposed on elite male basketball players during competitive matches. All players belonged to the same team, which competed in two official matches during a 2 -day tournament. The matches were played with 24 hours of rest between and conducted on the same court. Triaxial accelerometers (model ADXL326, Analog Devices, Inc., Norwood, U.S.A) were used to assess the physical demands of the two matches ( $\mathrm{N}=23$ match files). Variables were expressed relative to playing time in order to allow positional comparisons.

Player data were included for analysis provided they met the following criteria: (i) they did not suffer injury during the game and (ii) they played in the same position throughout the entire game (the players who occupied different positions within the same match were excluded from analyses). With these inclusion criteria, data were generated for 12 separate players, assigning each player to a certain position (Delextrat, et al., 2015): $\mathrm{PG}(n=4$ individual match files), SG ( $n=6), \mathrm{SF}(n=4), \mathrm{PF}(n=4)$ and C $(n=5)$.

The players wore a triaxial accelerometer unit (Figure 1) which detected and measured movement using a micro-electromechanical system. The unit was fitted to the upper back of each player using an adjustable harness (Figure 1). The devices were switched on $\sim 10$ minutes before each game and switched off immediately following the game completion. Accelerometer data were recorded at $100 \mathrm{~Hz}$ and transferred to a SD memory card for further analysis. As previously described in detail (Scanlan, et al., 2014), to validate the accelerometer's measurements of whole body movement, pilot tests were performed with same participants, with a correlation $(\mathrm{r}=0.96)$ between accelerometer external total load and running speed during treadmill-based incremental running $\left(7-15 \mathrm{~km} \cdot \mathrm{h}^{-1}\right)$. The reliability of the accelerometers has been acceptable both within (coefficient of variation, $\mathrm{CV}=1 \%$ ) and between devices $(\mathrm{CV}=1 \%)$ under controlled laboratory conditions, and between devices during field testing (CV=2\%; Boyd, et al., 2011). Thereby, accelerometers can be confidently utilized as a reliable tool to measure physical activity in team sports across multiple players and repeated bouts of activity (Boyd, et al., 2011; Scott, Black, et al., 2016). Further pilot data supported the reliability (intraclass correlation coefficient $[$ ICC $]=0.89$ and standard error of the mean $[\mathrm{SEM}]=0.08$ ) of the accelerometer total load model in the same players $(\mathrm{n}=8)$ during a typical 11-man fast break basketball exercise. This drill consisted of three players trying to score against two defenders on the court $(28 \times 14 \mathrm{~m})$ with rest/work time $\sim 1: 1$. When a shot has been taken (even if it results in a basket), the rebounder makes a quick outlet pass to either of the two players waiting near to the baseline who step inbounds from the sidelines to receive the outlet pass. The rebounder and these two players then break down the floor where the other two defenders are waiting to engage in play. After the shot, two new players enter the court for the outlet pass and the cycle continues.

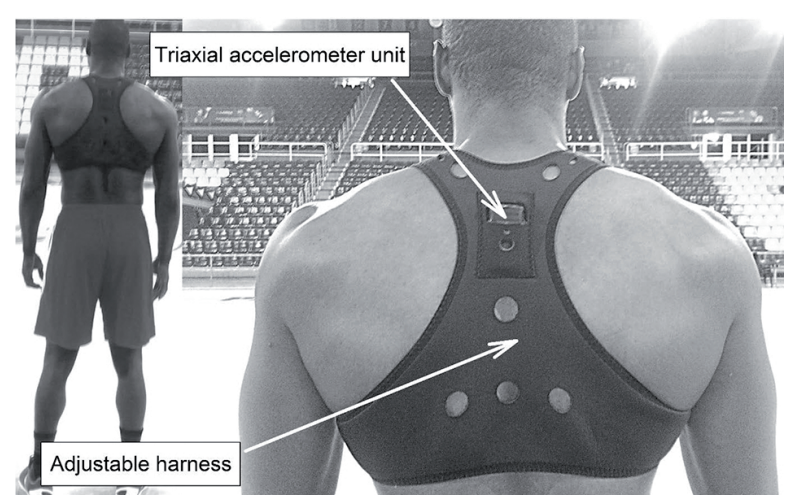

Figure 1. Triaxial accelerometer unit fitted to the upper back between the shoulder blades of each player using an adjustable harness.

The number of accelerations, decelerations, and external total load data from all players who participated in a game (at least $10 \mathrm{~min}$ ) were retained ( $\mathrm{n}=23$ files from 12 different players). After collection, all the match data were analysed with a software designed to provide objective measures of movement patterns and training load (Viper 2.6.0.0 Software). As in previous studies (Aughey, 2011), the occurrences of moderate accelerations/decelerations $\left(<3 \mathrm{~m} \cdot \mathrm{s}^{-2}\right)$ and maximal accelerations/ decelerations $\left(>3 \mathrm{~m} \cdot \mathrm{s}^{-2}\right)$ were recorded (Delaney, Cummins, Thornton, \& Duthie, 2017). Accelerations and decelerations in each band were calculated by identifying sudden increases/decreases in speed and continued increasing/decreasing for at least 0.5 $\mathrm{s}$. To be recognized as an acceleration/deceleration, the increases/decreases in speed identified must be greater than or equal to the user-defined value for moderate and maximal bands. As described previously, the set of body movements performed during match play was expressed as the accumulated total external load (Montgomery, et al., 2010). This estimate of physical demand combines the instantaneous rate of change in acceleration in three axes of body movement: 
up/down (z), side/side $(y)$ and forward/backward $(x)$ according to the formula:

$$
\left[(\mathrm{x})^{\mathrm{pf}}+(\mathrm{y})^{\mathrm{pf}}+(\mathrm{z})^{\mathrm{pf}}\right]^{*} 0.0001
$$

where $\mathrm{x}=\mathrm{g}$ force measure along the $\mathrm{x}$ axis, $\mathrm{y}=\mathrm{g}$ force measure along the $y$ axis, and $z=g$ force measure along the $\mathrm{z}$ axis are the orthogonal components of acceleration measured from the triaxial accelerometer directions at $100 \mathrm{~Hz}$. These values were then accumulated over the length of the match-play activity to obtain the external total load, which is reported in arbitrary units per minute of play. Only the number of accelerations and decelerations, external total load and the acceleration:deceleration ratio data during live time on the court were included in the analysis.

\section{Statistical analysis}

Data are presented as mean \pm standard deviation (SD). All data were first log-transformed to reduce bias arising from non-uniformity error. Possible differences or changes in variables within- and between-group were analysed for clinical significance using magnitude-based inferences by prespecifying 0.2 between-subject SDs as the smallest worthwhile effect (Hopkins, Marshall, Batterham, \& Haninn, 2009). The standardized difference or effect size (ES, 90\% confidence limit [90\%CL]) in the selected variables was calculated (Cohen, 1977). Threshold values for assessing magnitudes of the ES (changes as a fraction or multiple of baseline standard deviation) were $<0.20,0.20-0.60,0.6-1.2$,
1.2-2.0 and 2.0 for trivial, small, moderate, large and very large, respectively (Hopkins, et al., 2009). Quantitative chances of higher or lower changes were evaluated qualitatively as follows: $<1 \%$, almost certainly not; $1-5 \%$, very unlikely; $5-25 \%$, unlikely; 25-75\%, possible; 75-95\%, likely; 95-99\%, very likely; $>99 \%$, almost certain (Hopkins et al., 2009). A substantial effect was set at $>75 \%$ (SuarezArrones, et al., 2015).

\section{Results}

Moderate accelerations were almost certainly greater than moderate decelerations $(\mathrm{ES}=0.54$ to 3.12), and maximal decelerations were almost certainly greater than maximal accelerations in all playing positions (ES=2.70 to 6.87) (Table 1$)$.

SF showed fewer moderate accelerations than PG ( $\mathrm{ES}=0.37 \pm 0.21$, likely), $\mathrm{SG}(\mathrm{ES}=0.65 \pm 1.00$, likely) and $\mathrm{C}(\mathrm{ES}=0.67 \pm 1.32$, likely $)$, and fewer moderate decelerations than $\mathrm{C}(\mathrm{ES}=0.82 \pm 1.23$, likely). SF showed fewer maximal accelerations than $\mathrm{PG}(\mathrm{ES}=0.67 \pm 1.28$, likely), $\mathrm{PF}$ ( $\mathrm{ES}=1.29 \pm 1.26$, likely) and $\mathrm{C}(\mathrm{ES}=1.88 \pm 1.13$, very likely), and SG showed fewer maximal accelerations than PF (ES $=0.83 \pm 1.17$, likely) and $\mathrm{C}$ ( $\mathrm{ES}=1.20 \pm 1.03$, likely). SG had more maximal decelerations than $\mathrm{SF}(\mathrm{ES}=1.35 \pm 1.17$, likely), $\mathrm{PF}(\mathrm{ES}=0.91 \pm 1.17$, likely $)$ and $\mathrm{C}(\mathrm{ES}=0.64 \pm 1.07$, likely), and $\mathrm{PG}$ had more maximal decelerations than $\mathrm{SF}(\mathrm{ES}=0.93 \pm 1.23$, likely) and $\mathrm{PF}$ (ES=0.72 \pm 1.23 , likely) (Table 1).

Table 1. Acceleration and deceleration profiles (accelerometer-based) in elite professional basketball players and their external total load during competitive matches ( $n=23$ ); data are mean $\pm S D$

\begin{tabular}{|c|c|c|c|c|c|}
\hline \multirow[b]{2}{*}{ Variables } & \multicolumn{5}{|c|}{ Playing positions } \\
\hline & $\begin{array}{l}\text { Point guards } \\
\qquad(n=4)\end{array}$ & $\begin{array}{l}\text { Shooting guards } \\
\qquad(n=6)\end{array}$ & $\begin{array}{l}\text { Small forwards } \\
\qquad(n=4)\end{array}$ & $\begin{array}{l}\text { Power forwards } \\
\qquad(n=4)\end{array}$ & $\begin{array}{l}\text { Centers } \\
\quad(n=5)\end{array}$ \\
\hline $\begin{array}{l}\text { \# Accelerations } \\
\left(<3 \mathrm{~m} \cdot \mathrm{s}^{-2}\right) \\
\# / \mathrm{min}\end{array}$ & ${ }^{*} 29.6 \pm 3.9$ & ${ }^{*} 32.7 \pm 11.0$ & ${ }^{*} 26.7 \pm 2.6^{\mathrm{a}, \mathrm{b}, \mathrm{e}}$ & ${ }^{*} 28.0 \pm 5.0$ & ${ }^{*} 28.3 \pm 1.1$ \\
\hline $\begin{array}{l}\text { \# Accelerations } \\
\left(>3 \mathrm{~m} \cdot \mathrm{s}^{-2}\right) \\
\# / \mathrm{min}\end{array}$ & $1.4 \pm 0.9$ & $1.0 \pm 0.4^{\mathrm{d}, \mathrm{e}}$ & $0.8 \pm 0.3^{\mathrm{a}, \mathrm{d}, \mathrm{e}}$ & $1.4 \pm 0.5$ & $1.5 \pm 0.4$ \\
\hline $\begin{array}{l}\text { \# Decelerations } \\
\left(<3 \mathrm{~m} \cdot \mathrm{s}^{-2}\right) \\
\# / \mathrm{min}\end{array}$ & $23.8 \pm 3.6$ & $25.7 \pm 10.0$ & $21.7 \pm 2.2^{\mathrm{e}}$ & $24.0 \pm 4.6$ & $23.4 \pm 1.3$ \\
\hline $\begin{array}{l}\text { \# Decelerations } \\
\left(>3 \mathrm{~m} \cdot \mathrm{s}^{-2}\right) \\
\# / \mathrm{min}\end{array}$ & $+4.5 \pm 1.4$ & $+4.1 \pm 0.5$ & $+3.2 \pm 0.7^{a, b}$ & $+3.5 \pm 0.7^{a, b}$ & $+3.7 \pm 0.8^{b}$ \\
\hline $\begin{array}{l}\text { Acc : Dec Ratio } \\
\left(<3 \mathrm{~m} \cdot \mathrm{s}^{-2}\right)\end{array}$ & $1: 0.80 \pm 0.04^{\mathrm{d}, \mathrm{e}}$ & $1: 0.78 \pm 0.06^{\mathrm{c}, \mathrm{d}, \mathrm{e}}$ & $1: 0.81 \pm 0.01^{\mathrm{d}, \mathrm{e}}$ & $1: 0.86 \pm 0.02$ & $1: 0.83 \pm 0.02^{d}$ \\
\hline $\begin{array}{l}\text { Acc : Dec Ratio } \\
\left(>3 \mathrm{~m} \cdot \mathrm{s}^{-2}\right)\end{array}$ & $1: 3.94 \pm 1.3$ & $1: 4.87 \pm 1.8$ & $1: 4.26 \pm 0.8$ & $1: 2.67 \pm 0.4^{a, b, c}$ & $1: 2.57 \pm 0.5^{a, b, c}$ \\
\hline $\begin{array}{l}\text { External total load } \\
\text { (AU/min) }\end{array}$ & $4.8 \pm 1.1$ & $4.6 \pm 1.7$ & $4.8 \pm 0.8$ & $3.5 \pm 1.1^{\mathrm{a}, \mathrm{b}, \mathrm{c}, \mathrm{e}}$ & $4.4 \pm 0.3$ \\
\hline
\end{tabular}

Note. \#: number; Acc: accelerations; Dec: decelerations; AU: arbitrary units. *: Almost certainly difference vs. decelerations (<3m/ $\left.\mathrm{s}^{2}\right)$; +: Almost certainly higher vs. accelerations $\left(>3 \mathrm{~m} \cdot \mathrm{s}^{-2}\right)$.

a: substantial difference vs. point guards; b: substantial difference vs. shooting guards; c: substantial difference vs. small forwards; d: substantial difference vs. power forwards; e: substantial difference vs. centers. 
PF presented the highest acceleration-deceleration ratio $<3 \mathrm{~m} \cdot \mathrm{s}^{-2}(\mathrm{ES}=1.40$ to 2.22 , very likely in all cases), and $\mathrm{C}$ had a higher acceleration-deceleration ratio $<3 \mathrm{~m} \cdot \mathrm{s}^{-2}$ than $\mathrm{PG}, \mathrm{SG}$ and $\mathrm{SF}(\mathrm{ES}=0.71$ to 1.02 , likely in all cases). PG, SG and SF had a higher acceleration-deceleration ratio $>3 \mathrm{~m} \cdot \mathrm{s}^{-2}$ than $\mathrm{PF}$ and $\mathrm{C}(\mathrm{ES}=1.03$ to 2.21 , from likely to very likely). PF presented the lowest external total load of all specific playing positions ( $\mathrm{ES}=0.67$ to 1.18 , likely in all cases) (Table 1).

\section{Discussion and conclusions}

In this study, we examined the external total load, number of accelerations and decelerations, and acceleration:deceleration ratio between playing positions during basketball match play for the first time in professional male senior players. The main findings of the current study were: 1) the number of moderate accelerations was higher than the number of moderate decelerations, whereas the number of maximal decelerations was greater than the number of maximal accelerations in all playing positions; 2) the number of accelerations and decelerations at moderate and maximal speeds differed between playing positions $(\mathrm{PG}=\mathrm{SG}>\mathrm{SF})$; $3)$ the acceleration:deceleration ratio $\left(>3 \mathrm{~m} \cdot \mathrm{s}^{-2}\right)$ was significantly lower in players on the perimeter (PG and SG) than in PF and C, and 4) PF had the lowest total external load.

The observation of more moderate accelerations than moderate decelerations aligns with previous research (Puente, et al., 2017). Unfortunately, past research provides no information about the acceleration/deceleration threshold during basketball match play (Puente, et al., 2017). On the other hand, the presence of higher maximal decelerations than maximal accelerations in all playing positions likely highlights the importance of decelerations during high intensity actions aiming to obtain advantages during match play. Maximal decelerations may be especially necessary in performance of high intensity offensive actions such as quick changes of direction to avoid defenders during dribbling and before shooting. Maximal decelerations may also be used during defense to react quickly to actions performed by the opposing team during attacking play. Although maximal accelerations may be used to perform high intensity actions, maximal decelerations may be more frequently required by players in all positions to obtain advantage during technical and tactical tasks execution (Kempton, Sirotic, \& Coutts, 2016). This finding is mirrored in other sports where top team rugby players were shown to execute more high intensity decelerations $\left(<-2.78 \mathrm{~m} \cdot \mathrm{s}^{-2}\right)$ than sub-elite team rugby players (Kempton, et al., 2016). Accelerations and decelerations may be produced in different axes that correspond to different skills such as sprinting, changing direction, or jumping. Furthermore, more maximal decelerations can place notable mechanical stress on basketball players and may be associated with a greater eccentric muscular work that should be included in strength and conditioning programs, and in injury prevention programs.

Another prominent finding in the present study was the substantial difference in moderate and maximal accelerations and decelerations between playing positions. This result may partly be explained by the inherent technical and tactical requirements of each position and players' individual physical characteristics (Ben Abdelkrim, et al., 2007). Specifically, PG performed the highest number of decelerations at $>3 \mathrm{~m} \cdot \mathrm{s}^{-2}$, probably because players in this position make a high number of picks and hand to hand tactical actions. Similarly, SG performed more maximal decelerations than SF and PF, also likely due to a higher number of picks and hand to hand actions, but also possibly due to a higher number of screens they received to create open shooting opportunities. Maximal accelerations appear to be used by $\mathrm{PG}, \mathrm{PF}$ and above all by $\mathrm{C}$, probably because of the shorter duration of the actions in which they are involved (Puente, et al., 2017), with a lower maximal speed achieved during match play (Puente, et al., 2017). These accelerations and decelerations may be required in both offensive and defensive drills and may include horizontal acceleration and deceleration actions. For example, dribbling and crossover dribbling actions, but also vertical accelerations such as attacking the rim during offensive play.

The substantial difference in the acceleration: deceleration ratio $\left(>3 \mathrm{~m} \cdot \mathrm{s}^{-2}\right)$ between players on the perimeter ( $\mathrm{PG}$ and $\mathrm{SG}$ ) and $\mathrm{PF}$ and $\mathrm{C}$ suggests that these positions may require different playing styles, because PF and C occupy space closer to basket. From another perspective, the moderate acceleration:deceleration ratio per minute $\left(<3 \mathrm{~m} \cdot \mathrm{s}^{-2}\right)$ was similar to that recorded during a study of professional football match play (1.23 vs. 1.16) (Akenhead, et al., 2013), but the maximal acceleration:deceleration ratio $\left(>3 \mathrm{~m} \cdot \mathrm{s}^{-2}\right)$ was almost three times higher than in the football study (1.10 vs 0.34 ; Akenhead, et al., 2013). These results highlight the greater relevance of decelerations $>3 \mathrm{~m} \cdot \mathrm{s}^{-2}$ in basketball, likely as a consequence of court dimensions.

The position-specific total external load data revealed that, PF possessed the lowest value. This parameter contemplates the accelerations made by the basketball player in the three planes of movement, which makes it difficult to identify the cause of the results obtained. However, the lowest demand in PF during match play should be considered when design training exercises or sessions.

The data obtained in studies of official games should be considered, particularly in the management of the training load. If the external load requirements in official matches are quantified, 
in-season training load can be better periodized and prescribed (Gabbet, et al., 2016). This approach would allow us to determine the external total training load percentage for each training session relative to official game loads.

However, these results should be interpreted with caution. A small sample size of the current study is a limitation, especially the number of players per position; however, subjects were recruited from the Spanish First Division (ACB), which constitutes a small exclusive convenience sample. In the future, it is necessary to research the physical demands with more players evaluated. Moreover, the external load demands of basketball competition may be influenced by tactical factors, the score at a particular point in the game, and the quality of the opposition. Further research should try to determine whether there are any differences between professional and non-professional players, and also between different leagues (NBA vs. FIBA), ages (senior vs. junior) and sexes.

In conclusion, more maximal decelerations than accelerations were performed in all playing positions during elite basketball competition games. Furthermore, the acceleration:deceleration ratio $\left(>3 \mathrm{~m} \cdot \mathrm{s}^{-2}\right)$ was significantly lower in players on the perimeter (PG and SG) than in PF and C. This information should be taken into account in the design of strength/conditioning programs, emphasizing maximal deceleration movements in perimeter players and reducing the total external load on PF to best prepare players for match demands.

\section{References}

Ackland, T.R., Schreiner, A.B., \& Kerr, D. (1997). Absolute size and proportionality characteristics of World Championship female basketball players. Journal of Sports Sciences, 15(5), 485-490.

Akenhead, R., Hayes, P.R., Thompson, K.G., \& French, D. (2013). Diminutions of acceleration and deceleration output during professional football match play. Journal of Science and Medicine in Sport, 16(6), 556-561.

Aughey, R.J. (2011). Increased high-intensity activity in elite Australian football finals matches. International Journal of Sports Physiology and Performance, 6(3), 367-379.

Bale, P. (1991). Anthropometric, body composition and performance variables of young elite female basketball players. Journal of Sports Medicine and Physical Fitness, 31(2), 173-177.

Ben Abdelkrim, N., Castagna, C., Jabri, I., Battikh, T., El Fazaa, S., \& El Ati, J. (2010). Activity profile and physiological requirements of junior elite basketball players in relation to aerobic-anaerobic fitness. Journal of Strength and Conditioning Research, 24(9), 2330-2342.

Ben Abdelkrim, N., Chaouachi, A., Chamari, K., Chtara, M., \& Castagna, C. (2010). Positional role and competitivelevel differences in elite-level men's basketball players. Journal of Strength and Conditioning Research, 24(5), 1346-1355.

Ben Abdelkrim, N., El Fazaa, S., \& El Ati, J. (2007). Time-motion analysis and physiological data of elite under-19year-old basketball players during competition. British Journal of Sports Medicine, 41(2), 69-75.

Boyd, L.J., Ball, K., \& Aughey, R.J. (2011). The reliability of Minimaxx accelerometers for measuring physical activity in Australian football. International Journal of Sports Physiology and Performance, 6(3), 311-321.

Carling, C., Bloomfield, J., Nelsen, L., \& Reilly, T. (2008). The role of motion analysis in elite soccer. Sports Medicine, 38(10), 839-862.

Cohen, J. (1977). Statistical power analysis for the behavioral sciences. New York: Academic Press.

Cormery, B., Marcil, M., \& Bouvard, M. (2008). Rule change incidence on physiological characteristics of elite basketball players: A 10-year investigation. British Journal of Sports Medicine, 42(1), 25-30.

Delaney, J.A., Cummins, C.J., Thornton, H.R., \& Duthie, G.M. (2017). Importance, reliability and usefulness of acceleration measures in team sports. Journal of Strength and Conditioning Research. 2017 Feb 8. doi: 10.1519/ JSC.0000000000001849. [Epub ahead of print]

Delextrat, A., Badiella, A., Saavedra, V., Matthew, D., Schelling, X., \& Torres-Ronda, L. (2015). Match activity demands of elite Spanish female basketball players by playing position. International Journal of Performance Analysis in Sport, 15, 687-703.

di Prampero, P.E., Fusi, S., Sepulcri, L., Morin, J.B., Belli, A., \& Antonutto, G. (2005). Sprint running: A new energetic approach. Journal of Experimental Biology, 208(Pt 14), 2809-2816.

Dobson, B., \& Keogh, J. (2007). Methodological issues for the application of time-motion analysis research. Strength and Conditioning Research, 29, 48-55.

Gabbett, T.J. (2016). The training-injury prevention paradox: Should athletes be training smarter and harder? British Journal of Sports Medicine, 50(5), 273-280.

Gabbett, T.J., Wiig, H., \& Spencer, M. (2013). Repeated high-intensity running and sprinting in elite women's soccer competition. International Journal of Sports Physiology and Performance, 8(2),130-138.

Hoffman, J.R., \& Maresch, C.M. (2000). Physiology testing of basketball players. In W.E. Garrenty \& D.T. Kirkendall (Eds.), Exercise and sport science. Philadelphia: Lippincott Williams \& Wilkins.

Hopkins, W.G., Marshall, S.W., Batterham, A.M., \& Haninn, J. (2009). Progressive statistics for studies in sports medicine and exercise science. Medicine and Science in Sports and Exercise, 41(1), 3-13. 
Kempton, T., Sirotic, A., \& Coutts, A. (2017). A comparison of physical and technical performance profiles between successful and less-successful professional rugby league teams. International Journal of Sports Physiology and Performance, 12(4), 520-526.

Latin, R.W., Berg, K., \& Baechle, T. (1994). Physical and performance characteristics of NCAA Division I male basketball players. Journal of Strength and Conditioning Research, 8, 209-275.

Manzi, V., D’Ottavio, S., Impellizzeri, F.M., Chaouachi, A., Chamari, K., \& Castagna, C. (2010). Profile of weekly training load in elite male professional basketball players. Journal of Strength and Conditioning Research, 24(5), 1399-1406.

McInnes, S.E., Carlson, J.S., Jones, C.J., \& McKenna, M.J. (1995). The physiological load imposed on basketball players during competition. Journal of Sports Sciences, 13(5), 387-397.

Mero, A., \& Komi, P.V. (1987). Electromyographic activity in sprinting at speeds ranging from sub-maximal to supramaximal. Medicine and Science in Sports and Exercise, 19(3), 266-274.

Montgomery, P.G., Pyne, D.B., \& Minahan, C.L. (2010). The physical and physiological demands of basketball training and competition. International Journal of Sports Physiology and Performance, 5(1), 75-86.

Orchard, J. (2012). Who is to blame for all the football injuries? British Journal of Sports Medicine. Available: http:/ blogs.bmj.com/bjsm/2012/06/20/who-is-to-blame-for-all-the-football-injuries/

Ostojic, S.M., Mazic, S., \& Dikic, N. (2006). Profiling in basketball: Physical and physiological characteristics of elite players. Journal of Strength and Conditioning Research, 20(4), 740-744.

Pojskić, H., Šeparović, V., Užičanin, E., Muratović, M., \& Mačković, S. (2015). Positional role differences in the aerobic and anaerobic power of elite basketball players. Journal of Human Kinetics, 30(49), 219-227.

Puente, C., Abián-Vicén, J., Areces, F., López, R., \& Del Coso, J. (2017). Physical and physiological demands of experienced male basketball players during a competitive game. Journal of Strength and Conditioning Research, 31(4), 956-962.

Sallet, P., Perrier, D., Ferret, J.M., Vitelli, V., \& Baverel, G. (2005). Physiological differences in professional basketball players as a function of playing position and level of play. Journal of Sports Medicine and Physical Fitness, 45(3), 291-294.

Scanlan, A.T., Wen, N., Tucker, P.S., \& Dalbo, V.J. (2014). The relationships between internal and external training load models during basketball training. Journal of Strength and Conditioning Research, 28(9), 2397-2405.

Scott, T.J., Black, C.R., Quinn, J., \& Coutts, A.J. (2013). Validity and reliability of the session-RPE method for quantifying training in Australian football: A comparison of the CR10 and CR100 scales. Journal of Strength and Conditioning Research, 27(1), 270-276.

Scott, B.R., Lockie, R.G., Knight, T.J., Clark, A.C., \& Janse de Jonge, X.A.K. (2013). A comparison of methods to quantify the in-season training load of professional soccer players. International Journal of Sports Physiology and Performance, 8(2), 195-202.

Scott, M.T., Scott, T.J., \& Kelly, V.G. (2016). The validity and reliability of global positioning systems in team sport: A brief review. Journal of Strength and Conditioning Research, 30(5), 1470-1490.

Smith, H.K., \& Thomas, S.G. (1991). Physiological characteristics of elite female basketball players. Canadian Journal of Sports Sciences, 16(4), 289-294.

Soligard, T., Schwellnus, M., Alonso, J.M., Bahr, R., Clarsen, B., Dijkstra, H.P., Gabbett, T., ..., \& Engebretsen, L. (2016). How much is too much? (Part 1) International Olympic Committee consensus statement on load in sport and risk of injury. British Journal of Sports Medicine, 50(17), 1030-1041.

Suarez-Arrones, L., Núñez, J., Sáez de Villareal, E., Gálvez, J., Suarez-Sanchez, G., \& Munguía-Izquierdo, D. (2015). Repeated-high intensity running activity and internal training load of elite rugby sevens players during international matches: A comparison between halves. International Journal of Sports Physiology and Performance, 11(4), 495-499.

Varley, M.C., Fairweather, I.H., \& Aughey, R.J. (2012). Validity and reliability of GPS for measuring instantaneous velocity during acceleration, deceleration, and constant motion. Journal of Sports Sciences, 30(2), 121-127.

Submitted: March 1, 2017

Accepted: January 8, 2018

Published Online First: September 21, 2018

Correspondence to:

Jairo Vázquez-Guerrero

Medical Department and Performance \& Science

Department

Football Club Barcelona

Av. Aristides Maillol

08028 Barcelona, Spain

E-mail: jairo.vazquez@fcbarcelona.cat 